\title{
Thermal and Pressure Characterization of a Wind Tunnel Force Balance using the Single Vector System
}

\author{
Experimental Design and Analysis Approach to Model Pressure and Temperature Effects in \\ Hypersonic Wind Tunnel Research
}

\author{
Keith C. Lynn ${ }^{1}$, Sean A. Commo ${ }^{2}$, Thomas H. Johnson ${ }^{3}$, and Peter A. Parker ${ }^{4}$ \\ NASA Langley Research Center, Hampton, Virginia, 23681
}

\begin{abstract}
Wind tunnel research at NASA Langley Research Center's 31-inch Mach 10 hypersonic facility utilized a 5-component force balance, which provided a pressurized flow-thru capability to the test article. The goal of the research was to determine the interaction effects between the free-stream flow and the exit flow from the reaction control system on the Mars Science Laboratory aeroshell during planetary entry. In the wind tunnel, the balance was exposed to aerodynamic forces and moments, steady-state and transient thermal gradients, and various internal balance cavity pressures. Historically, these effects on force measurement accuracy have not been fully characterized due to limitations in the calibration apparatus. A statistically designed experiment was developed to adequately characterize the behavior of the balance over the expected wind tunnel operating ranges (forces/moments, temperatures, and pressures). The experimental design was based on a Taylor-series expansion in the seven factors for the mathematical models. Model inversion was required to calculate the aerodynamic forces and moments as a function of the strain-gage readings. Details regarding transducer on-board compensation techniques, experimental design development, mathematical modeling, and wind tunnel data reduction are included in this paper.
\end{abstract}

\section{Nomenclature}

$\begin{array}{ll}\text { AF } & =\text { Axial Force (lb) } \\ \text { AOA } & =\text { Angle of Attack } \\ \text { AMS } & =\text { Angle Measurement System } \\ \text { CCD } & =\text { Central Composite Design } \\ \text { FPS } & =\text { Force Positioning System } \\ \text { LaRC } & =\text { Langley Research Center } \\ \text { MSL } & =\text { Mars Science Laboratory } \\ \text { NASA } & =\text { National Aeronautics and Space Administration } \\ \text { NF } & =\text { Normal Force (lb) } \\ \text { PM } & =\text { Pitch Moment (in-lb) } \\ \text { RCS } & =\text { Reaction Control System } \\ \text { RM } & =\text { Roll Moment (in-lb) } \\ \text { RSM } & =\text { Response Surface Methodology } \\ \text { SF } & =\text { Side Force (lb) } \\ \text { SPD } & =\text { Split-Plot Design } \\ \text { SVS } & =\text { Single-Vector System }\end{array}$

${ }^{1}$ Research Engineer, Aeronautics Systems Engineering Branch, Mail Stop 238, Hampton, VA 23681, Member AIAA.

${ }^{2}$ Research Engineer, Aeronautics Systems Engineering Branch, Mail Stop 238, Hampton, VA 23681, Member AIAA.

${ }^{3}$ Research Engineer, Aeronautics Systems Engineering Branch, Mail Stop 238, Hampton, VA 23681, Member AIAA.

${ }^{4}$ Research Scientist, Aeronautics Systems Engineering Branch, Mail Stop 238, Hampton, VA 23681, Senior Member AIAA. 
$\mathrm{YM} \quad=$ Yaw Moment (in-lb)

\section{Introduction}

A recent wind tunnel test conducted at the NASA Langley Research Center (LaRC) 31-Inch Mach 10 facility used the SS-12 force balance to measure the aerodynamic loads on the test model. The test was performed on a scale model of the Mars Science Laboratory (MSL) aeroshell to determine the interaction between the on-board reaction control system (RCS) exit flow and the free-stream flow. During entry into the Mars atmosphere, MSL will utilize the RCS to control both the rate damping and guidance maneuvers. ${ }^{1,2}$ When the RCS jets are fired, the exit flow is released into a complex wake of the vehicle. The interaction between the two flows can potentially have adverse effects on the aerodynamics of the aeroshell. Therefore, it is critical that these effects are fully understood and characterized. The series of wind tunnel tests performed at the 31-Inch Mach 10 facility employed a test matrix that was designed to explore the interaction between the RCS exit flow and the wake of the vehicle over the hypersonic regime of flight.

The SS-12 is a flow-thru type force balance, which allows a pressurized gas to be routed down the center of the balance and out through the model to the RCS nozzles. The experimental setup for the wind tunnel test is shown in Figure 1. An initial series of tests at the Mach-10 facility were previously conducted to obtain force/moment data for a similar model configuration with similar RCS nozzle geometries. The SS-12 balance was used during the initial series of tests when several issues were discovered.

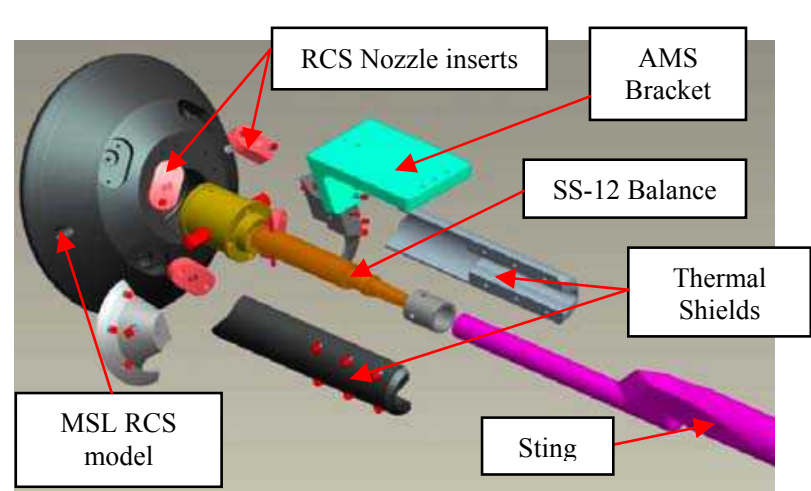

Figure 1. MSL test configuration setup (SS-12 balance shown as part of assembly)

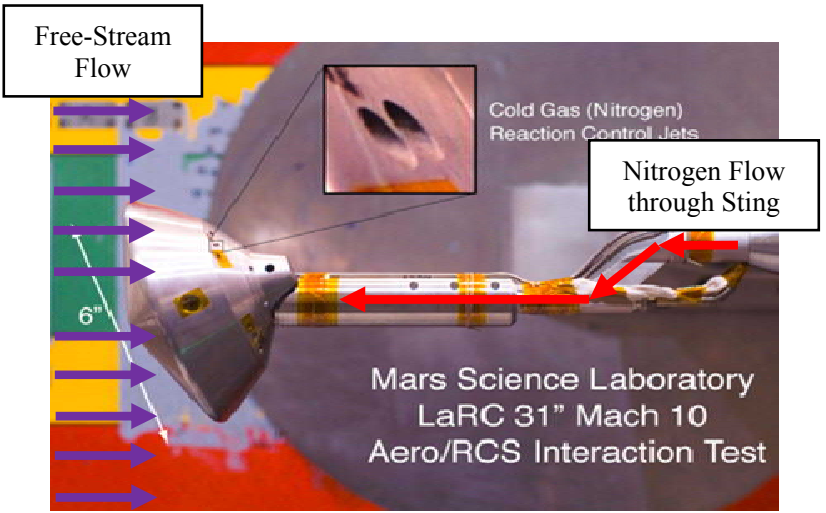

Figure 2. MSL test at 31" Mach 10, using SS-12 balance

The first issue regarded an electrical zero offset reading that was discovered on both the side force (SF) and yawing moment (YM) balance outputs, which occurred during testing. These electrical zero shifts were uncovered after repeated model injections (using the model injection mechanism, which rapidly injects the model into the oncoming free-stream flow), signifying that one (or both) of the following situations occurred during testing: 1) the strain gages located on the balance might have delaminated due to dynamic over-loading or 2) the balance measurements beams were slightly bent due the dynamic over-loading during the model injection process. Figures 3 $\& 4$ show the balance 'zero' outputs, and a shift in the SF and YM outputs is observed to the right of the dashed line in each figure.

The second anomaly that was observed during initial testing was the temperature drift behavior of the balance over the course of each 120 -second tunnel run. It was discovered that all of the force and moment measurement data from the SS-12 balance drifted as the temperature of the balance increased from the nominal temperature ( 70degrees Fahrenheit). Several different test scenarios were run to evaluate the magnitude of these effects. During the first scenario, the model and the balance were soaked at Mach 10, a dynamic pressure of 2.198 psia, and an angle of attack of -20 degrees while the RCS jets were injected with 120 psia nitrogen gas. Over the course of the 120-second blow-down cycle of the tunnel, both the forward and aft thermocouples located within the balance drifted from a temperature of 70 degrees Fahrenheit to roughly 85 degrees Fahrenheit. The results from this test are shown in Figure 5 (red curve - pitching moment coefficient history, green curve - applied pressure to RCS jets, orange curve - forward balance thermocouple temperature, brown curve - aft balance thermocouple temperature). 
As seen from this figure, the pitching moment coefficient, which is a measure of the longitudinal stability of the vehicle, output drifted from 0.0365 to 0.0338 (27 counts) as the temperature of the balance increased. Similar behaviors were observed in many of the other balance outputs during the constant pressure soaking runs.

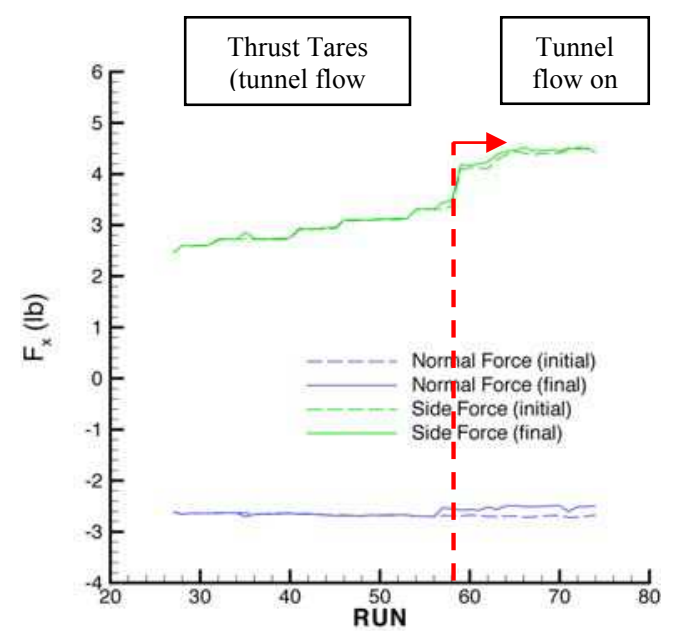

Figure 3. SS-12 Force Component Electrical Zeros

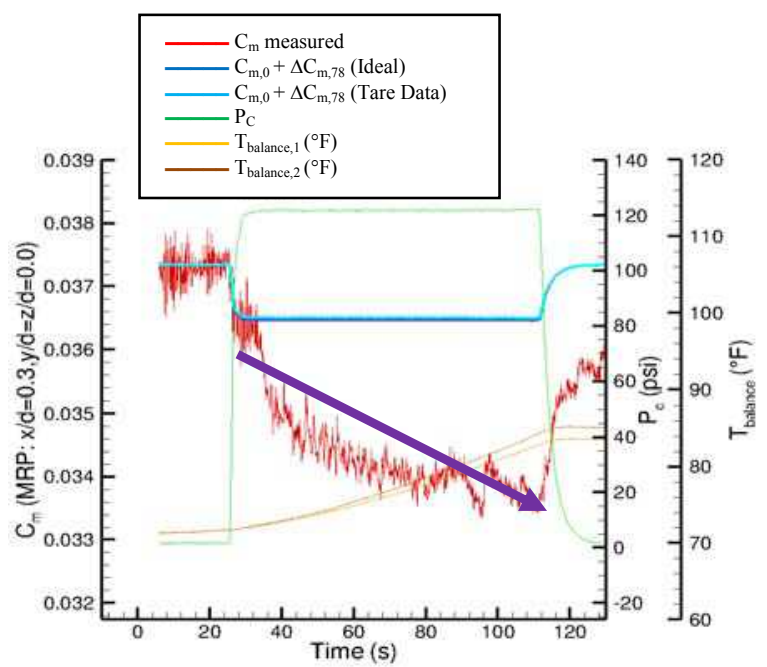

Figure 5. Single Block Soak Run (Pitch Moment History)

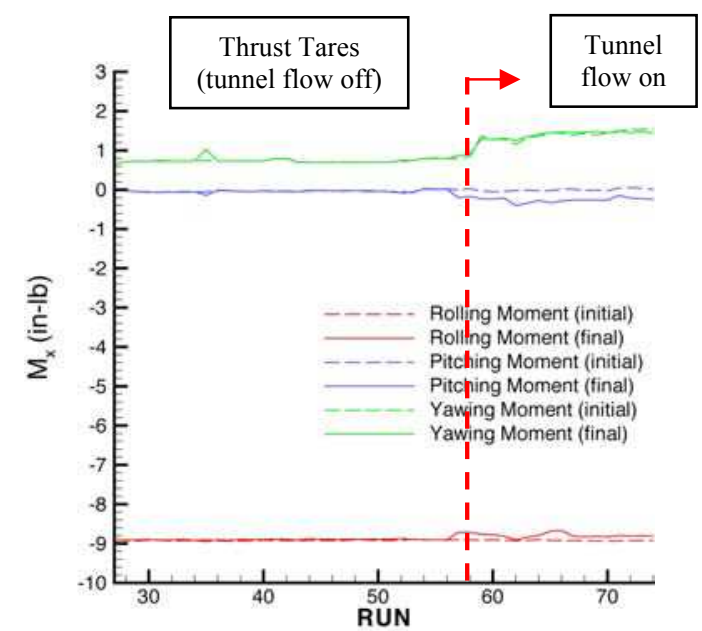

Figure 4. SS-12 Moment Component Electrical Zeros

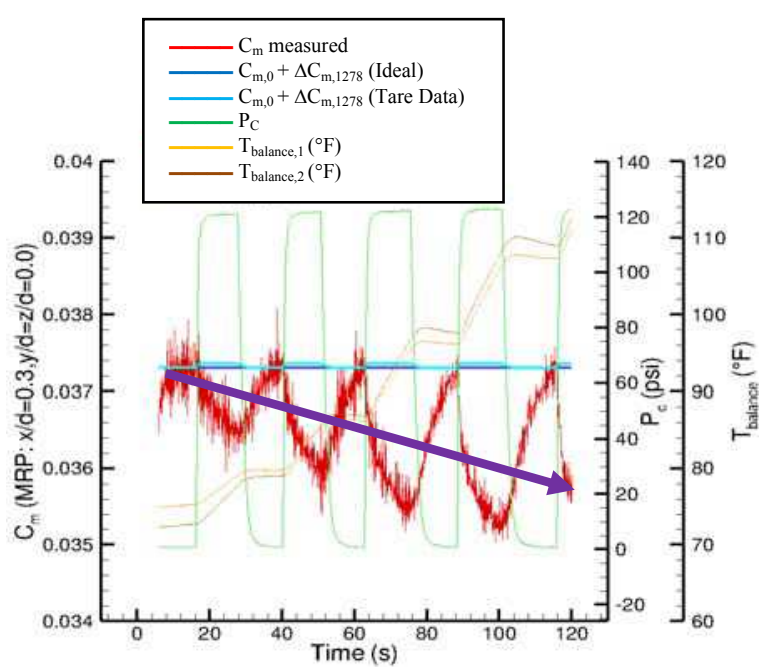

Figure 6. Pressure Cycle Run (Pitch Moment History)

The second scenario evaluated the drift behavior of the balance while the model was subjected to specified RCS jet firing sequences over the duration of the 120-second blow down cycle of the tunnel. During the 120 seconds of testing, approximately four pressure cycles were completed, where the specified RCS were turned on and off four times (off $=0$ psia, on $=120$ psia). While these cycles were executed, both the forward and aft thermocouple outputs, as well as the resulting forces and moments responses on the balance outputs, were measured. Figure 6 shows that both the forward and aft balance temperatures increased from 70 degrees Fahrenheit to approximately 112 degrees Fahrenheit over the duration of the test run. Additionally, as the pressure to the RCS jets was cycled on and off, the temperature of the balance increased, which caused a negative drift in the measurement outputs.

It is evident from Figures 3-6 that the balance exhibited some non-ideal behaviors, which resulted in poor data quality from these series of tests. The temperature drift issues were significant enough that the researchers were not confident in the data, as the drift issues induced resulting moment measurements that were often on the same order 
of magnitude as the torques created by the RCS jets. Test engineers and researchers were forced to re-evaluate the test setup, along with the overall design and calibration techniques used for the characterization of the balance. The following sections provide detail on the design configuration of the balance used during the first tunnel entry, along with changes to both the instrumentation design of the balance and details on the design of a new method for characterizing the balance for this specific wind-tunnel test.

\section{Force Balance Calibration \& Design}

\section{A. Balance Basics}

The fundamental instrument that is used to directly measure the aerodynamic loads on a wind tunnel model is known as a force balance. The force balance is a transducer that is capable of providing high-precision measurements of forces and moments in six degrees of freedom. The underlying purpose of wind tunnel testing is to understand the performance characteristics of an aircraft or spacecraft (with different model configurations) in an environment that closely simulates 'true' flight conditions. In order to adequately determine these model performance characteristics, it is crucial that a measurement device be used during the wind tunnel test that is capable of accurately and precisely measuring the aerodynamic loads imparted on the test model.

The most critical portion of the balance design process is the characterization of the balance. The purpose is to develop a mathematical model that characterizes the performance of the

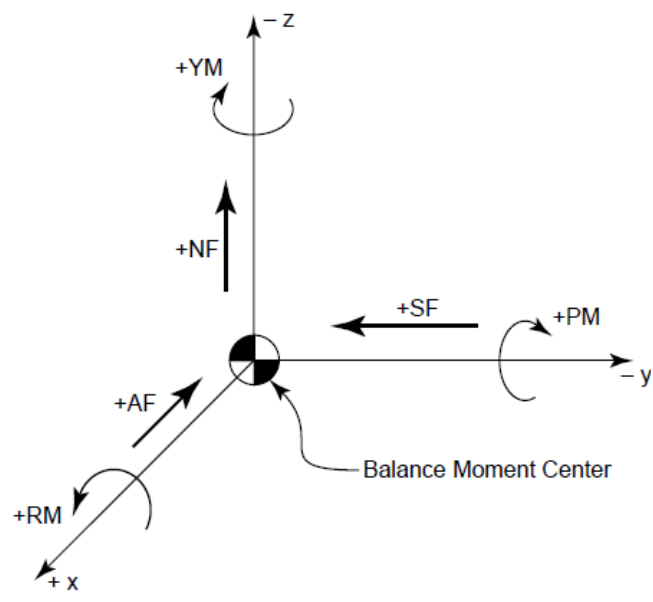

Figure 7: Balance Coordinate System balance. In return, this mathematical model can be used to estimate the aerodynamic loads imparted on the model during the wind tunnel test. As a general procedure, when characterizing a force balance, a set of pre-determined independent variables (applied calibration loads) are applied to the balance, and the resulting dependent variables (electrical output response of each measurement bridge) are recorded. The range of the calibration loads applied to the balance during the calibration process defines the design space. Historically, the load schedule used to characterize a balance (which defines the load combinations and the order that they are to be performed) has been a standardized process that is the same for most balance types. NASA LaRC's traditional method for calibrating any balance is based on a second-order Taylor series approximation (6 linear main-effect terms, 15 two-factor interactions and 6 pure quadratic terms) to represent the functional relationship between the applied calibration loads and the bridge response voltages. ${ }^{3}$ The standard balance coordinate system shown in Figure 7 is used to define the applied loads and moments.

The second-order Taylor series approximation in six factors used to develop the mathematical model is

$$
y=\beta_{o}+\sum_{i=1}^{k} \beta_{i} x_{i}+\sum_{i=1}^{k} \sum_{j=i+1}^{k} \beta_{i j} x_{i} x_{j}+\sum_{i=1}^{k} \beta_{i i} x_{i}{ }^{2}
$$

$k$ is the number of independent variables, $x_{i}$ is the ith independent variable, and the $\beta$ s represent the calibration coefficients determined from ordinary least squares regression. The calibration coefficients are then delivered to the researchers at the wind tunnel.

When characterizing any balance, it is critical to perform a sufficient number of independent calibration loads such that the interactions present within the balance can be fully determined. As stated previously, the processes in place at NASA LaRC for calibrating balances allow for computing both the linear and the higher-order interaction terms for the calibration model. The linear interactions that are present within a balance are the result of several factors including: machining errors, errors in both location and alignment of strain-gages, and variations in the gage factor for the strain-gages, etc. ${ }^{4}$ The second-order interaction terms are typically associated with the magnitude of the deflections present during loading of the balance. ${ }^{4}$ Typical balance calibrations at NASA LaRC have all been conducted with only applied loads as being the calibration factors, but it is possible to include other factors, such as pressure and temperature, within the calibration design if it is suspected that they have effects on the responses. 
It is possible to reduce the overall impact of the interaction terms, by performing the following steps:

1. Thermally compensating all wheat-stone bridges (apparent strain correction)

2. Gage matching all strain gages within a bridge, to match the thermal characteristics of each gage

3. Precisely machine the balance, ensuring all features and tolerances match theoretical 'perfect' design

4. Optimize balance such that deflections are minimized, while sensitivity remains at an acceptable level (difficult to do since balance deflections directly relate to measurement sensitivity, for strain gage balances)

\section{B. Balance Calibration Techniques}

There are primarily three different types of calibration systems used today: automated calibration machines ${ }^{5}$, manual calibration stands and the single-vector-system (SVS) ${ }^{6}$. Each system employs a different load schedule based upon the capabilities of the respective hardware. Using pneumatically applied loads, automated machines have the ability of collecting vast amounts of data in very little time. Accordingly, the experimental designs (load schedules) for this system are typically quite large (on the order of 1000 calibration loads). Manual test stand systems are similar to automated machines except that gravity based loads (dead-weights) are used instead of pneumatically applied loads. Manual stand systems apply on the same order of runs as an automated machine but requires much more time.

Both the automated and manual stand systems were designed around the one-factor-at-a-time (OFAT) calibration design methodology. Weaknesses of this approach have led engineers to develop experimental designs sweeping two factors simultaneously, necessary to calculate interaction coefficients of the mathematical model. ${ }^{7}$ Without using a rigorously statistical approach, the experimental designs created for the manual and automated systems contain a vast number of runs that exhaust all combinations of two-component loads. The costs associated with executing these designs are further increased when including other factors, such as pressure and temperature, in the calibration. Fully crossing pressure and temperature with these experimental designs can more than quadruple the required number of runs, which could take months to complete using a manual test stand system.

The current SVS load schedule is a variation of a central composite design (CCD) prominent in response surface methodology (RSM). ${ }^{8,9}$ For these designs, the load schedule can be separated into two portions: factorial and axial. The factorial portion of the load schedule consists of 37 runs where all six components are loaded simultaneously. The axial portion consists of 27 runs that loads one or two components at a time. A 28-term second-order model is fit using these 64 runs. A feasible pressure and temperature calibration could be conceived by crossing the 64 run design at different levels of pressure and temperature; however, this research took further steps to make the design even more efficient. The relatively low number of runs utilized by the SVS makes it a suitable means for calibrating at temperature and pressure.

\section{SS-12 Balance Design}

The SS-12 balance is a monolithic 5-component water-cooled flow-thru force balance that measures NF, PM, RM, YM, and SF. The balance was originally designed to be a direct read balance (resolves NF, PM, SF, YM, RM, directly), which is typically referred to as a $2 \mathrm{~F} / 3 \mathrm{M}$ balance. The original balance was instrumented to be parallel wired with a common voltage excitation input for all 5-components.. Table 1 shows the full-scale design loads for the balance.

Table 1. SS-12 Balance Design Loads

\begin{tabular}{|c|c|}
\hline Component & Design Load \\
\hline $\mathrm{NF}$ & $100 \mathrm{lbs}$ \\
\hline $\mathrm{AF}$ & $\mathrm{n} / \mathrm{a}$ \\
\hline $\mathrm{PM}$ & $150 \mathrm{in}-\mathrm{lbs}$ \\
\hline $\mathrm{RM}$ & $32 \mathrm{in}-\mathrm{lbs}$ \\
\hline $\mathrm{YM}$ & $40 \mathrm{in}-\mathrm{lbs}$ \\
\hline $\mathrm{SF}$ & $30 \mathrm{lbs}$ \\
\hline
\end{tabular}

By using a flow-thru balance, high-pressure nitrogen (or other gases) can be supplied to the model to simulate RCS jet firing. Instead of using a pressure bellows configuration to route the high-pressure nitrogen to the model, the nitrogen is pumped through an internal cavity in the sting and in the balance. Then the gas is routed through the 
internal passageways in the model out to the RCS nozzles. This particular balance was designed for testing at hypersonic facilities, which typically involves high temperatures being induced on the balance due to the heat transfer rate from the speed of the free-stream flow onto the exterior surface of the model. The balance was designed with an active cooling shield, which provides cooling to the measurement beams of the balance by continuously circulating cold water around the external surface of the balance, to help alleviate these issues.

Previous testing with this model and balance configuration revealed large temperature gradients that were present along the length of the balance. Since this model is being tested in the 31-Inch Mach-10 facility, the speed of the free-stream air is so high that when the air flow passed over the MSL model, it was interacting with the aft sting, and the resultant heat transfer into the sting occurred at such a rapid rate that the nitrogen flowing through it was heated. While the aft (non-metric) end of the balance is being heated rapidly due the heated nitrogen flowing through it, the forward (metric) end of the balance is being cooled by the cold water being circulated through the cooling tube jacket. The two extreme temperatures at the opposite ends of the balance resulted in large temperature gradients over the length of the balance during the 120-second runs. The presence of these large temperature gradients within the measurement sections of the balance caused the strain gages to see large thermally induced apparent strains, which were misinterpreted as aerodynamic loads being imparted onto the balance. Therefore, the resulting aerodynamic load measurements being recorded by the balance during the test were affected so much that the data was not accurate.

These large temperature gradients resulted in repeatability issues with the measurement performance of the balance. After the original wind tunnel test, it was decided to re-instrument the balance with new strain gages, and the bridge configuration was changed from the standard direct-read configuration to the standard force balance configuration (resolves NF1, NF2, SF1, SF2, RM). With this new bridge configuration the individual strain gages that make up a Wheatstone bridge are located at a single axial location, which reduces the sensitivity of the output responses due to thermal effects. As with any instrument, changing the configuration of the gage locations requires that the balance be re-characterized.

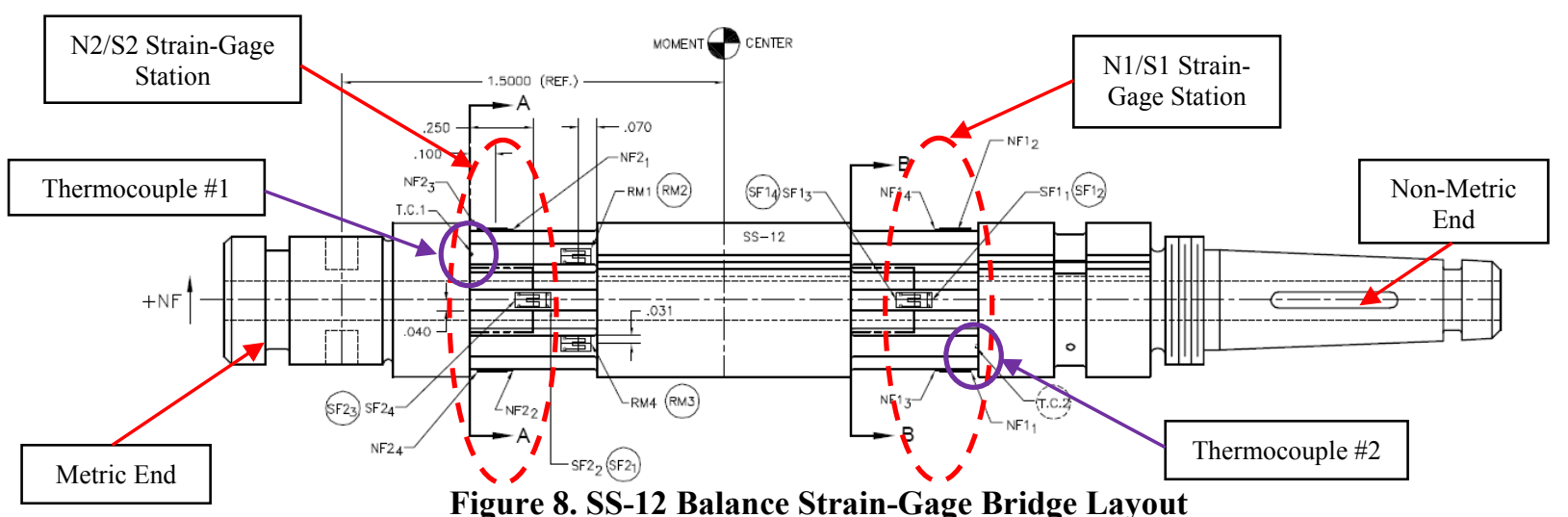

\section{Calibration Experimental Design}

\section{Balance Calibration Experimental Design}

For calibration applications, the limitations of the calibration apparatus cannot be ignored when developing an experimental design. The most important phase of an experiment is the pre-experimental planning, where the goals, response variables, and input factors of the experiment are established. Based on the objectives and possible outcomes of an experiment, a successful approach can be formulated. Most force balance characterization applications at NASA LaRC utilize response surface techniques, in which the system is reasonably well-understood and delivering a mathematical model is required. However, in instances where no previous system knowledge is available, a preliminary, factor-screening experiment can be conducted to eliminate unimportant factors before the comprehensive characterization experiment. This approach is known as sequential experimentation and is a strategic and rigorous approach often used in experimental design., 
The response variables are the parameters that are measured during an experiment. In force balance calibration, the response variables are the strain-gage outputs (response variables for the described calibration are shown in Table 3). The input factors can be divided into four types: controlled design factors, held-constant factors, uncontrolled factors, and nuisance factors. Controlled design factors are varied during the experiment over specified ranges to study their effects on the response variables (controlled design factors for this calibration are shown in Table 2). Held-constant and uncontrolled factors are not studied during an experiment because the effects on the responses due to these factors are small and assumed to be negligible. Nuisance factors can be controlled or uncontrolled but their effect on the responses may not be small. While these factors may not be of interest, it should be recognized that they are present, and precautions should be taken to limit their effect. Blocking is a useful technique in limiting the effect of nuisance factors. For force balance calibrations using the SVS, physics-based and hardware constraints dictate the possible combinations of the design factors, which are typically the six applied loads.

When designing an experiment, three concepts are emphasized: randomization, replication, and blocking. Randomization defends against systematic errors in an experiment. Because the runs are executed randomly, any effects due to hysteresis, or other systematic behaviors, are minimized. Replication provides information about the pure experimental error of the response variables. For a given set of factor combinations that is replicated $n$ times, then there are $n-1$ degrees of freedom available to estimate the repeatability, which is an important statistic in any calibration. Finally, as mentioned earlier, blocking is a preventative technique that is used to minimize the effect of any lurking variables in the experiment. Blocks are organized such that orthogonality of the factors is retained in the design matrix. The current SVS calibrations incorporate a randomized block design.

Table 2. Design Factors

\begin{tabular}{|c|c|c|}
\hline Factor Label & Design Factor (units) & Range \\
\hline A & Normal Force (lbs) & -100 to +100 \\
\hline B & Pitching Moment (in-lbs) & -150 to +150 \\
\hline C & Rolling Moment (in-lbs) & -32 to +32 \\
\hline D & Yawing Moment (in-lbs) & -40 to +40 \\
\hline E & Side Force (lbs) & -30 to +30 \\
\hline F & Average Balance Temperature $\left({ }^{\circ} \mathrm{F}\right)$ & 70 to 120 \\
\hline G & Balance Cavity Pressure $(\mathrm{psia})$ & 14.7 to 400 \\
\hline
\end{tabular}

Table 3. Design Responses

\begin{tabular}{|c|c|}
\hline Response & Response Type (units) \\
\hline 1 & Normal Force Bridge Output $(\mu \mathrm{V} / \mathrm{V})$ \\
\hline 2 & Pitching Moment Bridge Output $(\mu \mathrm{V} / \mathrm{V})$ \\
\hline 3 & Rolling Moment Bridge Output $(\mu \mathrm{V} / \mathrm{V})$ \\
\hline 4 & Yawing Moment Bridge Output $(\mu \mathrm{V} / \mathrm{V})$ \\
\hline 5 & Side Force Bridge Output $(\mu \mathrm{V} / \mathrm{V})$ \\
\hline
\end{tabular}

Characterizing the SS-12 force balance to meet the objectives of the researchers posed two new challenges. Since the SS-12 does not contain strain-gages for axial force measurements, a reduced version of the current SVS calibration design could have been used. In addition, the more formidable challenge was incorporating two new design factors. A simple but highly inefficient solution would have been to cross the reduced SVS design with every possible combination of the pressure and temperature factors. Instead, a brand new experimental design was developed which utilized many aspects of the original calibration design for a six-component force balance on the SVS with some advanced response surface techniques.

Any characterization that involves temperature is very expensive due to the time associated with making the change and waiting for the temperature to stabilize. In the NASA LaRC force measurement laboratory, it takes approximately two hours before the force balance reaches a steady-state temperature. However, changes to the other six factors of interest are significantly cheaper. Restricting the randomization in temperature provides vast benefits over a completely randomized design, including increased experimental efficiency and reduction in associated costs. Split-plot designs (SPD) were developed for instances when hard-to-change factors are present in an experiment. The ideology and concepts of an SPD are attributed to the agricultural heritage in which they were developed. 
Hard-to-change factors in agricultural experiments were large plots of land and were conveniently called whole plots. The easy-to-change factors were crops within a large plot of land and became known as subplots. In this calibration, the whole plot factor, temperature, is randomized and the six subplot factors (NF, SF, RM, PM, YM and Pressure) are randomized while the temperature is held constant. Because every whole plot contains the same subplot design, the SPD is fully crossed, which has some particularly powerful statistical properties. Special consideration of the error analysis is required when using a split-plot design. ${ }^{10-13}$ The analysis of the SPD is done with Restricted Maximum Likelihood (REML). Originally developed for the analysis of mixed models, REML is applicable to the analysis of a SPD because of the fixed and random components in the design. Additionally, the restriction on randomization contributes a second variance component which REML is able to estimate. Using this method, total model uncertainty is estimated by summing the contributions of subplot and whole plot error.

$$
\begin{gathered}
y=a+\beta_{T} T+\beta_{P} P+\beta_{T P} T P+\beta_{P P} P^{2}+\beta_{T P P} T P^{2}+\sum_{j=1}^{n} \beta_{j} F_{j}+\sum_{j=1}^{n} \beta_{j j} F_{j}^{2}+\sum_{j=1}^{n} \sum_{k=j+1}^{n} \beta_{j k} F_{j} F_{k}+\sum_{j=1}^{n} \beta_{j}^{t e m p} T F_{j} \\
+\sum_{j=1}^{n} \beta_{j j}^{t e m p} T F_{j}^{2}+\sum_{j=1}^{n} \beta_{j}^{\text {pres }} P F_{j}+\sum_{j=1}^{n} \beta_{j}^{\text {pres }} P^{2} F_{j}+\sum_{j=1}^{n} \beta_{j j}^{\text {pres }} P F_{j}^{2}
\end{gathered}
$$

Based on the calibration design matrix, the supported 51-term calibration model is given in Equation (2). It can be seen that the strain-gage output, $y$, is a function of temperature, pressure and applied forces/moments. Five calibration models are developed for the five output responses, resulting in a [51 x 5] calibration matrix. The model is an augmentation of the second-order Taylor series approximation given by Equation (1). It was formulated on the assumption that temperature has a linear main effect and interaction, while pressure has a linear and quadratic effect and interaction. The assumption that temperature has primarily a liner effect on the response of each measurement component is based on the experience of expert balance engineers, and previous experiments conducted to obtain temperature corrections for the linear sensitivities obtained during the standard balance calibration. Accordingly, temperature has two levels $\left(70^{\circ} \mathrm{F}, 120^{\circ} \mathrm{F}\right)$ in the experimental design while pressure has four $(14,7,120,200,400$ psia). Three factor interactions that include two forces and one pressure or temperature were purposefully omitted from this model because historical results showed that linear and quadratic terms have the dominate effect. This allowed for the implementation of a smaller, more efficient design matrix necessary to support a 51-term model, as opposed to a 71-term model.

The entire experimental design required 8 days to complete the 1,028 runs (breakdown of runs during calibration shown in Table 4). Each day consisted of one block in the design, accompanied by confirmation points and a tare sequence performed at the beginning and end of the day. For each tare sequence, five tare models were constructed for each level of pressure and temperature, which describes the nominal response of a bridge as a function of balance orientation. The tare models were implemented such that at a given temperature and pressure, the appropriate tare model was applied in the data reduction. The calculated tare loads were then added to the applied loads, resulting in a true load that was finally used to develop the model in Equation (2).

Table 4. Number of Runs for Each Subset Type

\begin{tabular}{|l|cc|ccccccc|}
\hline & \multicolumn{2}{|c|}{ Original } & \multicolumn{7}{|c|}{ Modified } \\
\hline & Day 1 & Day 2 & Day 3 & Day 4 & Day 5 & Day 6 & Day 7 & Day 8 & Total \\
\hline Tare Runs & 36 & 24 & 96 & 96 & 96 & 96 & 96 & 96 & 636 \\
Calibration Runs & 42 & 0 & 46 & 41 & 45 & 43 & 45 & 43 & 305 \\
Confirmation Runs & 0 & 20 & 12 & 11 & 11 & 11 & 11 & 11 & 87 \\
\hline Temperature (deg. F) & 77 & 77 & 120 & 120 & 77 & 77 & 120 & 120 & - \\
Pressure Levels & 1 & 1 & 4 & 4 & 4 & 4 & 4 & 4 & \\
\hline
\end{tabular}

***Note: Day 1 and Day 2 is the original SVS experimental design for 5-component force balance (no pressure and temperature effects)

The entire design was a combination of a 62-run room temperature and pressure experiment, and a 392-run split-plot design that was performed at multiple levels of pressure and temperature. The split-plot design was 
executed on days 3 through 8 , while the more typical 5-component design was carried out over the first two days. If temperature and pressure effects were neglected, then the 62-run design would have been sufficient to develop a second-order model. The smaller design also provided a benchmark for the accuracy of the balance. The combination of these two designs allowed for orthogonal estimation of all model terms.

\section{E. Properties of Experimental Design}

When creating the experimental design for characterizing the SS-12 force balance, three important properties were examined. These properties aid in the robustness of the design and are

- Variance inflation factor

- Leverage

- Standard error of prediction (prediction variance)

Variance inflation factor (VIF) is a measure of the collinearity that exists between regression coefficients within the mathematical model. ${ }^{14-16}$ It is a generally accepted in the balance community to set the upper limit of 5-10 on the $\mathrm{VIF}^{14,16}$. A VIF of 1 implies complete orthogonality among the regressor variables. The presence of multicollinearity within a linear regression directly impacts the precision in which regression coefficients can be estimated, so any values of VIF greater than 10 indicates possible flaws within the experimental design.

Table 5 lists the VIF values for the experimental design for the SS-12 balance calibration. As seen from the table, it is clear that the estimated VIF values NF*YM and SF*PM coefficients are highly inflated due to multicollinearity issues within the design. The following paragraphs provide some detail on why these particular coefficient combinations exhibit high multicollinearity issues. The VIF estimates for all other coefficients are considered to be acceptable for the calibration design.

Table 5. SS-12 Calibration Design Properties (VIF \& Standard Error)

\begin{tabular}{|c|c|c|c|c|c|}
\hline Term & $\begin{array}{l}\text { Std } \\
\text { Error }\end{array}$ & VIF & Term & $\begin{array}{c}\text { Std } \\
\text { Error }\end{array}$ & VIF \\
\hline Normal & 0.1413 & 2.8895 & Side*Temp & 0.0958 & 1.1820 \\
\hline Pitch & 0.2306 & 2.8421 & Side*Pres & 0.1294 & 1.2622 \\
\hline Roll & 0.4548 & 11.3423 & Temp*Pres & 0.0833 & 1.1959 \\
\hline Yaw & 0.1330 & 1.1400 & Normal`2 $_{2}$ & 0.2304 & 3.9524 \\
\hline Side & 0.1489 & 2.9188 & Pitch^2 & 0.2716 & 2.7517 \\
\hline Temp & 0.1591 & 7.5294 & Roll^2 & 0.2671 & 2.6756 \\
\hline Pres & 0.1796 & 5.5845 & Yaw $^{\wedge} 2$ & 0.2325 & 2.6419 \\
\hline Normal*Pitch & 0.1465 & 1.0997 & Side $^{\wedge} 2$ & 0.1821 & 3.3289 \\
\hline Normal*Roll & 0.2241 & 2.6183 & Temp^2 $^{\wedge}$ & 1.2217 & 1.9223 \\
\hline Normal*Yaw & 171.8389 & 88992.9801 & Pres`2 $^{\wedge}$ & 0.1289 & 1.2407 \\
\hline Normal*Side & 0.4005 & 1.4953 & Normal` $2 *$ Temp & 0.2372 & 7.9871 \\
\hline Normal*Temp & 0.0904 & 1.1869 & Normal` $2 *$ Pres $^{\prime}$ & 0.2815 & 6.4526 \\
\hline Normal*Pres & 0.1189 & 1.1989 & Normal*Pres^2 & 0.1837 & 2.8719 \\
\hline Pitch*Roll & 1.1879 & 1.1593 & 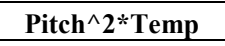 & 0.2760 & 3.5760 \\
\hline Pitch*Yaw & 0.7892 & 1.6237 & Pitch^2*Pres & 0.3342 & 2.8884 \\
\hline Pitch*Side & 193.3513 & 89046.4120 & Pitch*Pres`2 $^{\wedge}$ & 0.3008 & 2.7672 \\
\hline Pitch*Temp & 0.1558 & 1.3098 & Roll^2*Temp & 0.2584 & 3.1825 \\
\hline Pitch*Pres & 0.2091 & 1.3351 & Roll^2*Pres & 0.3333 & 2.8923 \\
\hline Roll*Yaw & 1.1472 & 1.7814 & Roll*Pres^2 & 0.3104 & 3.0705 \\
\hline Roll*Side & 0.6948 & 1.4793 & Yaw^2*Temp & 0.2193 & 2.8789 \\
\hline Roll*Temp & 0.1530 & 1.2949 & Yaw^ $^{\wedge} *$ Pres & 0.2821 & 2.8078 \\
\hline Roll*Pres & 0.1945 & 1.1851 & Side^2*Temp & 0.1894 & 5.4633 \\
\hline Yaw*Side & 0.1636 & 2.0056 & Side $^{\wedge} 2 *$ Pres & 0.2301 & 4.6476 \\
\hline Yaw*Temp & 0.1340 & 1.1142 & Side $^{*}$ Pres`2 $^{\wedge}$ & 0.1879 & 2.6890 \\
\hline Yaw*Pres & 0.1763 & 1.1572 & Temp*Pres^2 & 0.1270 & 2.8904 \\
\hline
\end{tabular}

The SVS calibration methodology is based on applying a single load vector to the balance, where a system of forces and moments are reduced to a single resultant force vector acting at a point. For this to occur, the system of 
applied forces and moments must be able to be reduced such that the resultant force and moment vectors are mutually perpendicular to each other. In doing so, an infinite number of possible load combinations can be applied to a balance during calibration, but any arbitrary combination of both forces and moments cannot be applied. This limitation on arbitrary load combinations is a physical constraint of the SVS system. The perpendicular relationship that exists between resultant force and moment vectors is expressed at the dot product between the two vectors, and by setting the cosine of the angle between the two equal to zero, the resulting relationship is established (for a 6component balance $)^{6}$ :

$$
\frac{-(R M)(A F)+(P M)(S F)-(Y M)(N F)}{\left(\sqrt{R M^{2}+P M^{2}+Y M^{2}}\right)\left(\sqrt{A F^{2}+S F^{2}+N F^{2}}\right)}=0
$$

The governing equation which constrains the relative direction and magnitude of each of the applied load components using a single load vector is ${ }^{6}$ :

$$
-(R M)(A F)+(P M)(S F)-(Y M)(N F)=0
$$

This physical constraint of the SVS signifies possible load combinations that cannot be independently applied during a balance calibration ( $\mathrm{RM} / \mathrm{AF}, \mathrm{PM} / \mathrm{SF}, \mathrm{YM} / \mathrm{NF})$. Therefore, there exists no possible combination of force/moment vectors that can be applied during an SVS calibration that result in a load point where only AF/RM, $\mathrm{PM} / \mathrm{SF}$, or YM/NF are applied. Because this constraint within the SVS exists, collinearity exists between the three interaction terms within the calibration model. For the calibration of the SS-12 balance (5-component balance) the $\mathrm{RM} / \mathrm{AF}$ constraint does not exist, because the balance does not have an $\mathrm{AF}$ component.

Leverage of an experimental design provides a measure of how influential any single observation (calibration point) within the design affects the resulting regression model, and results from the distribution of that point within the design space of the parameter (response) under investigation. ${ }^{9,14}$ If a particular design has all points randomly and equally distributed throughout the design space of the parameter being considered, the leverage values for all calibration points will be fairly uniform. If a particular point in the calibration design is located outside of the design space, or at an extreme point within the design space of the parameter being considered, this point will generally have a much higher leverage than other points. Figure 9 plots out the computed leverage value for each of the calibration runs within the SPD calibration, and it can be seen that the leverage values are randomly distributed and uniform over the calibration, revealing a good experimental design. Only a few of the calibration load points fall outside of the $2 *$ average leverage threshold.

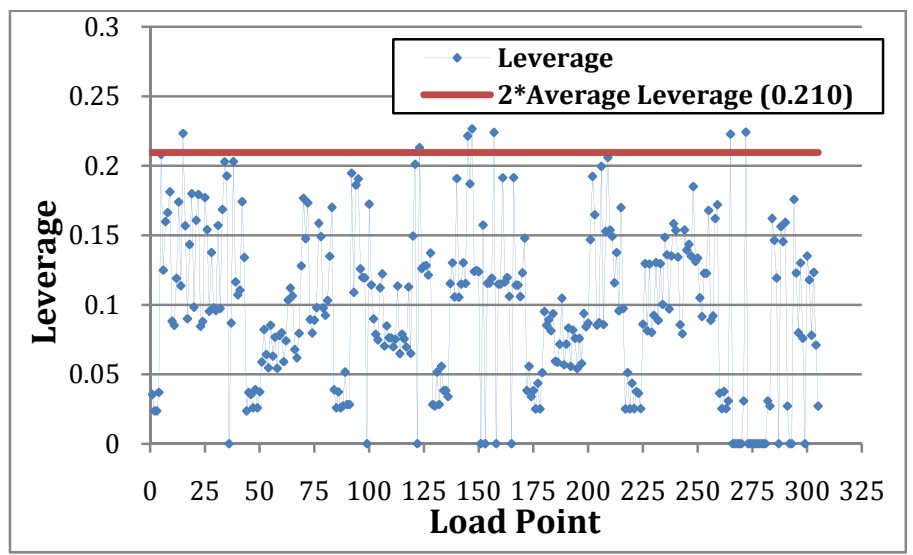

Figure 9. Calibration Data Point Leverage Values

The standard error of prediction, or prediction variance, is a computed value that provides a rough estimate on the quality of the predicted responses, based entirely on the experimental design. ${ }^{15}$ By looking at the relative distribution of the points throughout the design space, values for the prediction variance can be computed for each point. For a CCD, the computed values are especially sensitive to the location of the axial (single-loaded) points 
within the design space, as well as the quantity of center runs that are executed. ${ }^{15}$ Response surface plots are an efficient method to check the prediction variance of a design. Ideally, the surface should be flat, which signifies constant prediction properties across the entire design space. As seen from the figures below for the SS-12 design, it is apparent that the plots exhibit different characteristics based on the factor combinations and the experimental design. Figure 10a shows the standard error contours for the NF/PM factor combinations and the response surface for the error predictions over the design space is fairly flat. The flatness of the response surface signifies that the error predictions are fairly uniform over the entire design space for the NF/PM factor combination. Figure 10b shows the standard error contours for the SF/RM factor combination, and reveals that as you get to the edges of the design space the error prediction increases (indicated by the end points tailing up).

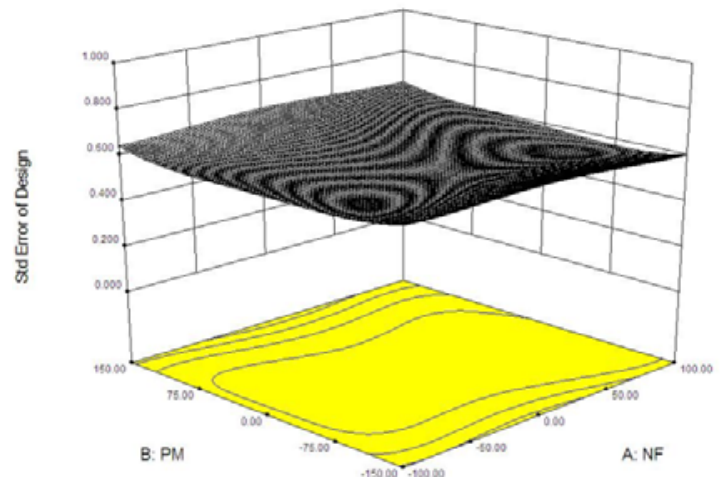

a)

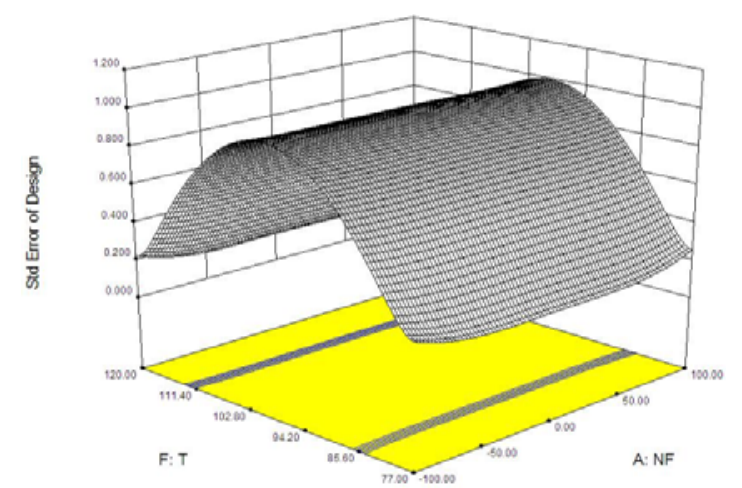

c)

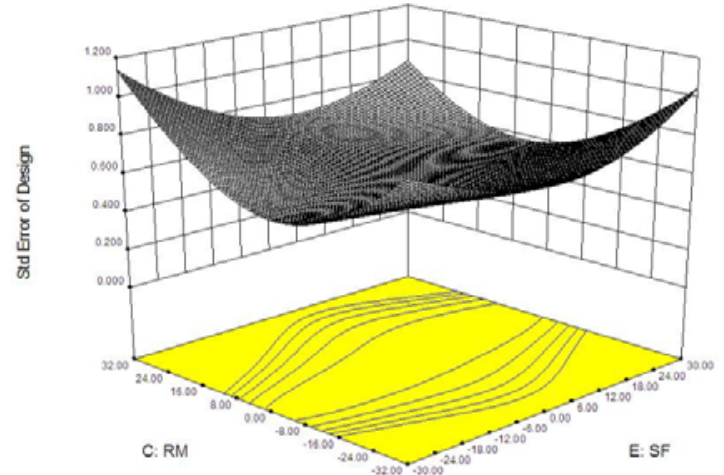

b)

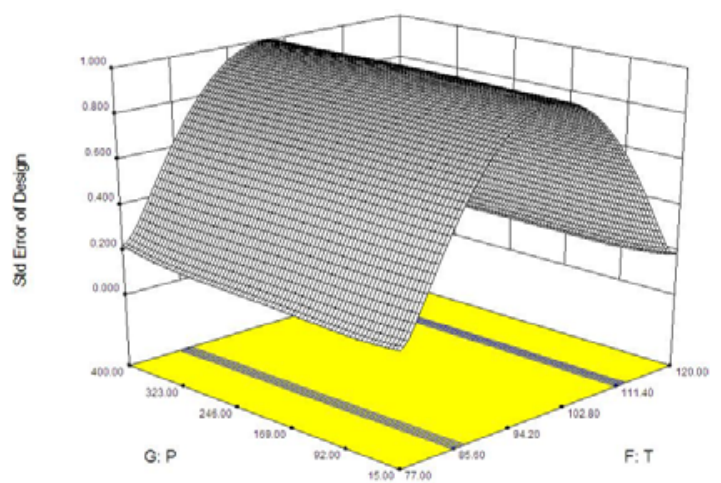

d)

Figure 10. Standard Error plots; a) NF/PM, b) SF/RM, c) NF/Temp, d) Temp/Pres

Figures 10c and 10d show the response surfaces for the NF/Temperature and Temp/Pressure factor combinations over the design ranges for each factor. Both response surface curves exhibit a behavior known as the 'stationary ridge', where the standard error maximum falls along a line (line maximum) in the temperature plane, and the values for the standard error decrease toward their minimum value as you extend into the NF and pressure planes. While the standard error plots shown in Figures 10c and 10d are not flat over the design space for the shown factors, the range of the standard error prediction is within an acceptable limit. It can be seen in Figures 10c and 10d that the temperature factor setting only had two discrete settings within the calibration, represented by the bands at the bottom of each 3D plot. The bands represent regions where the temperature factor setting was set during the calibration runs, therefore the standard error predictions are lower at these points, and the error prediction increases as move toward the center where no points were taken.

\section{Calibration Execution \& Data Analysis}

\section{F. Calibration Setup}

The hardware and experimental setup for the calibration of the SS-12 balance is shown in Figures 11 and 12 . The balance is installed inside of its balance calibration block, and the SVS template is installed onto the balance 
calibration block. The balance calibration block has a specially designed cap plate that mounts to its forward most end, which caps off the balance and calibration block allowing the system to be statically pressurized up to 600 psia. This assembly was then mounted to the SVS backstop, which is attached to a set of motors that allow the balance to both pitch and roll to any specified set of angles, allowing the balance to be positioned at any position in space. In order to calibrate the balance at specific pressure/temperatures, the standard SVS calibration configuration was modified to accept these new calibration features.

In order to apply constant static pressures to the internal cavity of the balance, the taper adapter that was used to mount the balance to the SVS back-stop was modified to add a thru hole with a tapped hole at its aft end to accommodate a pressure fitting. A k-bottle of compressed nitrogen ( 2400psia) was connected to the taper adapter, and a digital pressure gage was placed in-line between the k-bottle and the balance. The digital pressure gage was wired into the data acquisition system, and the pressure measurement at each calibration load point was precisely measured to within $0.1 \mathrm{psia}$. During the calibration process a second technician varied the applied static pressure by adjusting the valves on the nitrogen cylinder, and monitoring the output on the digital pressure gage. It should be noted that the static pressure setting applied to the balance for all calibration points was adjusted between each data point, even for back-to-back data points that required the same pressure to be applied to the balance. This is an important concept to note, as when there are replicated data points that randomly occur back-to-back within the experimental design, in order for these points to be truly replicated the applied factor settings must be adjusted off of their nominal setting, then adjusted back to the setting for that particular replicate (i.e., for back-to-back replicates where the pressure is to remain 400 psia, the pressure is adjusted off of the nominal 400 psia by some pre-determine amount (say 385 psia), and then adjusted back to 400 psia). This is a critical feature of replicated design points within any experimental design.

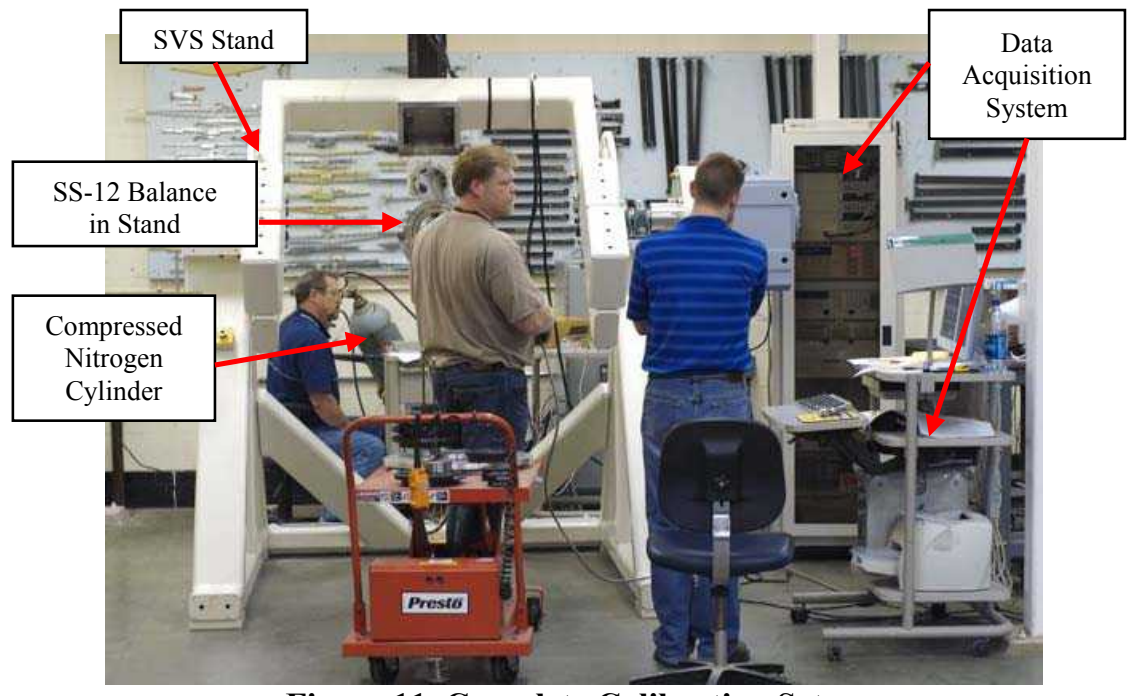

Figure 11. Complete Calibration Setup

To simulate test conditions where the balance is at a steady-state temperature, a heater system was developed that allows both the balance and the back-stop of the SVS to be heated to some constant elevated temperature. To raise the temperature and SVS back-stop to this elevated temperature, a series of foil heaters were applied to the balance calibration block and the back-stop directly aft of where the balance mounts to the SVS. These heaters are attached to an active control system, which actively controls the temperature being applied to the balance using a series of thermocouples that feedback the local temperatures at the heaters. During this process the thermocouples located in the forward and aft sections of the balance are monitored, and the heater control system is adjusted to ensure the average temperature between the forward and aft cage sections is maintained within an acceptable range $\left(1-2^{\circ} \mathrm{F}\right)$ of the nominal temperature setting necessary for the calibration load schedule.

Figure 12 shows the foil heater arrangement, and gives detail on the experimental setup used to apply all loads, static cavity pressure, and steady-state temperatures to the balance throughout the calibration process. 

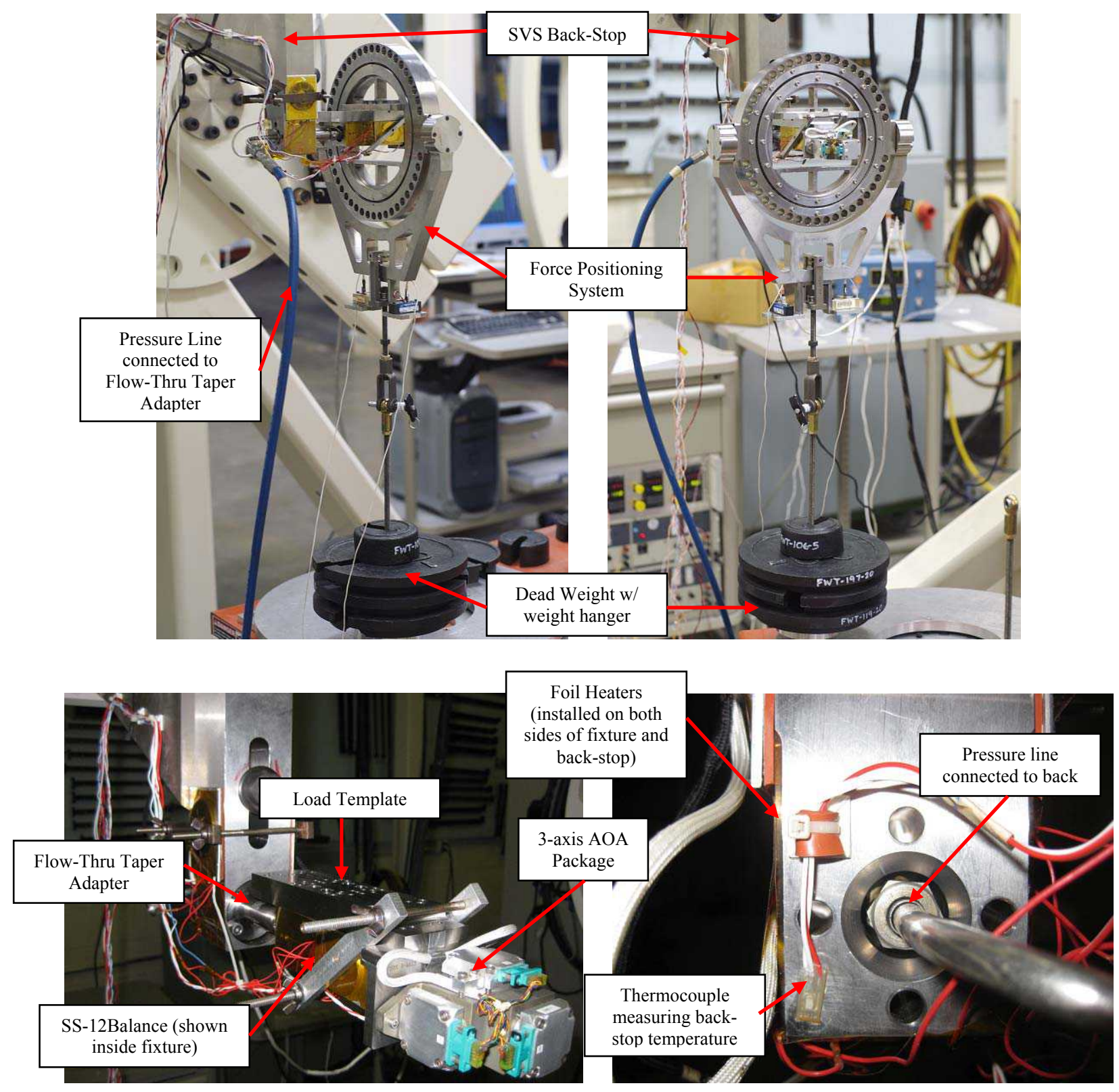

Figure 12. SS-12 SVS Calibration Setup, a) rear view of balance and FPS, b) front view of balance and FPS, c) close-up view of calibration setup, $d$ ) rear view showing pressure line attachment to the balance taper adapter

The load combinations explored during the calibration are depicted in Figure 13, revealing the combinations for all load points used during both the original design ( 62 runs) and the modified design (392 runs). These plots show the different load combinations that were explored, revealing how the load combinations were dispersed for each of the load measurement components throughout the design space of the balance. The loads and moments shown in each of the plots are the measured tare corrected loads, crossed with other loads/moments, pressures and temperatures. 

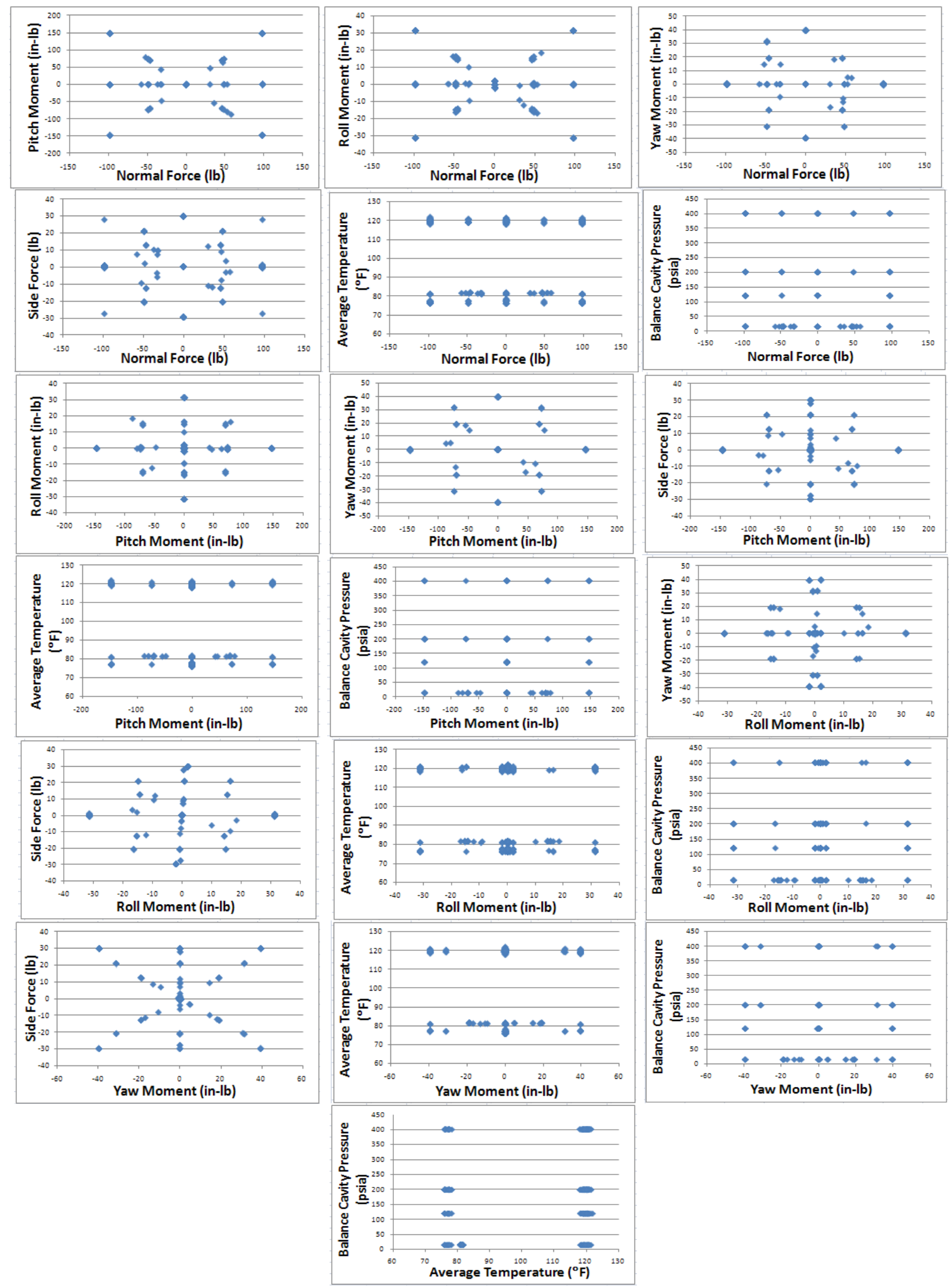

Figure 13. Load Combination Plots 14

$49^{\text {th }}$ AIAA Aerospace Sciences Meeting 


\section{G. Data Analysis}

Preliminary uncertainty analysis of the calibration model revealed that subplot error dominated whole-plot error (the revelation that the subplot error dominated the design signified that the calibration data could be treated as a completely randomized design for all further analysis). Consequently, the REML was not required, and traditional uncertainty methods were adopted for the remainder of the analysis. The 51 term model was reduced using a backwards selection method (model term hierarchy not applied during model reduction ${ }^{17}$ ), using a $95 \%$ level of confidence. All calibration data were converted over to coded factor units during the analysis, and converted back to engineering units at the completion of analysis. The full-scale outputs and measurement sensitivities for each bridge are shown in Table 6 .

Table 6. Full-Scale Outputs \& Linear Sensitivities

\begin{tabular}{cccccc}
\hline & NF & PM & RM & YM & SF \\
\hline Full Scale Output (mV/V) & 2.649 & 2.959 & 0.700 & 3.532 & 1.989 \\
\hline Linear Sensitivity (lb/mV/V) & 37.746 & 50.689 & 45.714 & 11.325 & 15.083 \\
\hline
\end{tabular}

Figures 14 and 15 show the percent of full-scale effect for each model term. Full scale effects are calculated as the percentage of size a given coefficient is compared to the sensitivity for that response model. The sensitivities are removed from Figure 14 because they are considered $100 \%$ of the full scale effect. The figures are presented separately since the terms including pressure and temperature are about one order of magnitude smaller than the terms without pressure and temperature.
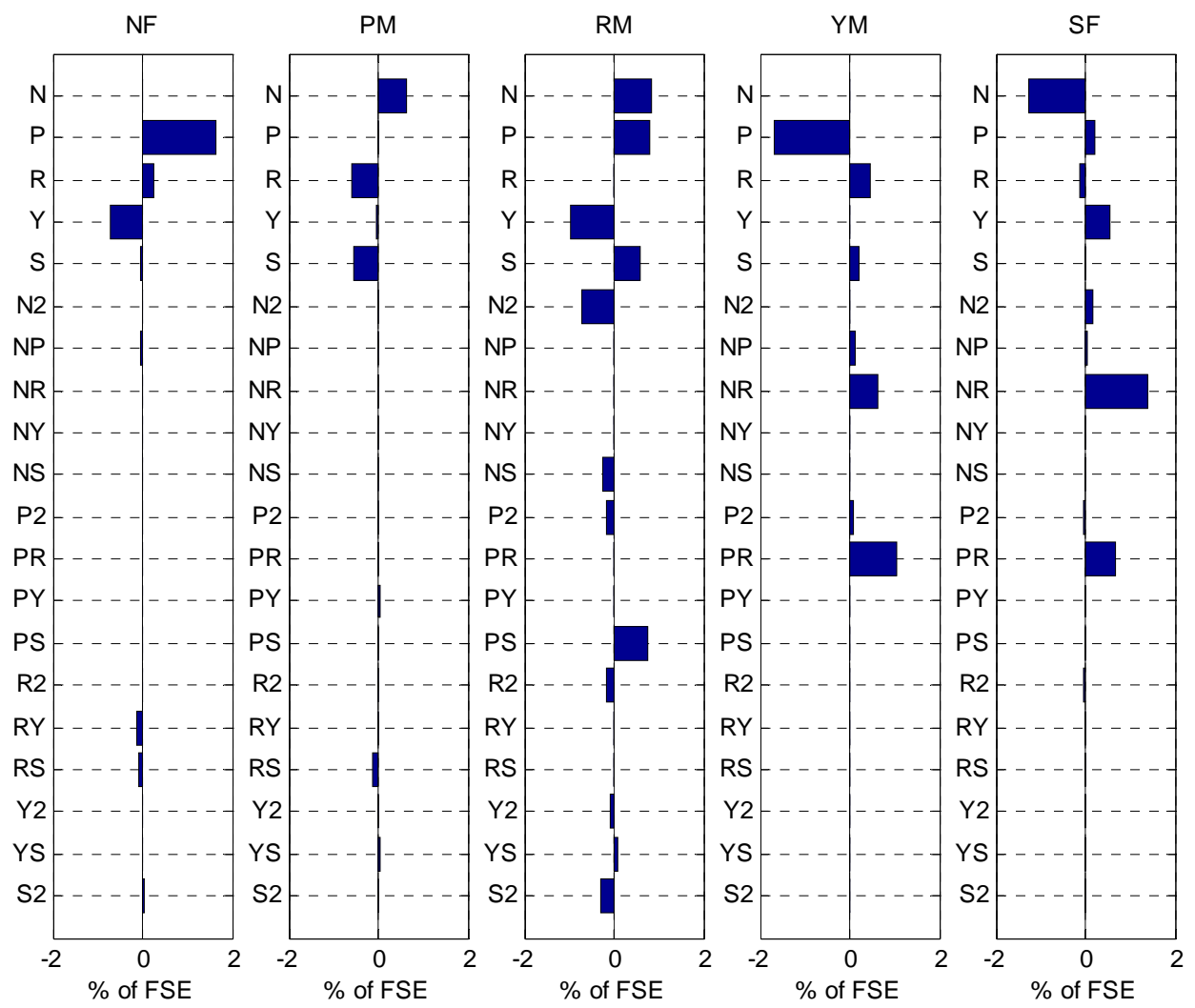

Figure 14. Percent of Full Scale Effects; Excluding Pressure and Temperature Terms 

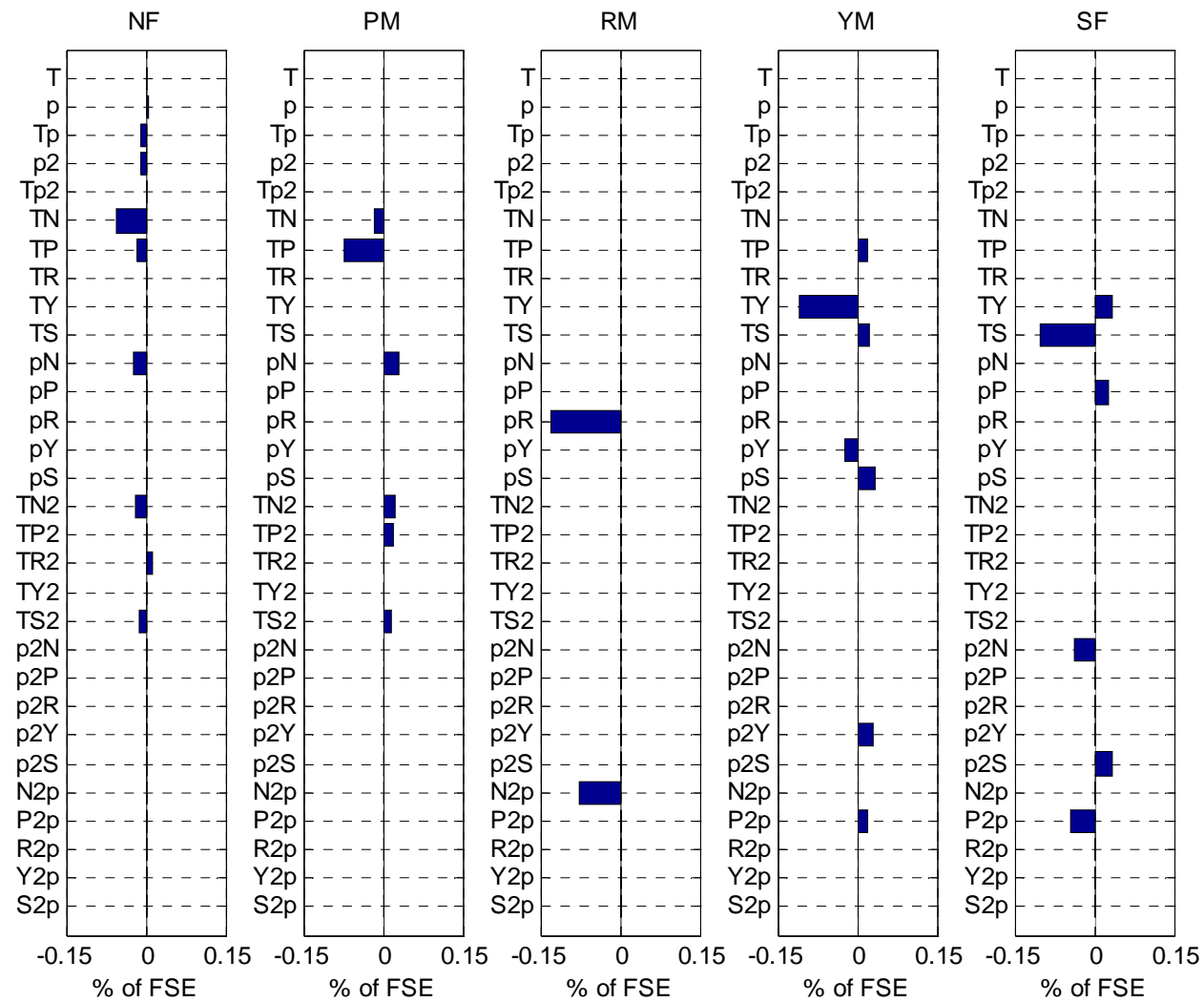

Figure 15. Percent of Full Scale Effects; Pressure and Temperature Terms Only

In Figure 15, "p" corresponds to the applied balance cavity pressure, while "P" corresponds to pitching moment. As seen in Figure 15, the linear pressure effects are almost all zero, except for a small pressure effect in the normal force model. Due to balance being a 5-component flow-thru design (no axial force), we would expect the pressure influence to me minimal on the performance of the balance. The absence of any significant temperature linear effects could be attributed to the thermal correcting properties of the Wheatstone bridges and/or the gage matching technique ${ }^{18}$ used at NASA Langley Research Center.

Table 7. Contributions of Percentages of Full Scale Effects

\begin{tabular}{rccccc}
\hline & NF (\%) & PM (\%) & RM (\%) & YM (\%) & SF (\%) \\
\hline Linear Force Interactions & 2.649 & 2.959 & 0.700 & 3.532 & 1.989 \\
2FI and Quadratic Interactions & 0.291 & 0.241 & 2.510 & 1.876 & 2.393 \\
Pressure \& Temperature Interactions & 0.159 & 0.179 & 0.206 & 0.257 & 0.282 \\
\hline
\end{tabular}

From Table 7 it is evident that the interaction effects are small compared to the sensitivities. The linear force interactions are the largest group, but they are still only on the order of one percent the size of the sensitivities. Pressure and temperature are the smallest group, accounting for about $0.2 \%$ of the full scale effect for each measurement component. Table 8 demonstrates that pressure and temperature account for about $5 \%$ of the interaction effects for each response model.

Table 8. Contributions of Interaction Effects

\begin{tabular}{rccccc}
\hline & NF (\%) & PM (\%) & RM (\%) & YM (\%) & SF (\%) \\
\hline Linear Force Interactions & 86 & 88 & 21 & 62 & 43 \\
2FI and Quadratic Interactions & 9 & 7 & 73 & 33 & 51 \\
Pressure \& Temperature Interactions & 5 & 5 & 6 & 5 & 6 \\
TOTAL & 100 & 100 & 100 & 100 & 100 \\
\hline
\end{tabular}


Both experimental design points and confirmations points were used to calculate the standard deviation between the applied loads and the loads calculated from the regression models. The experimental design contained 305 runs, with 87 confirmation points interspersed throughout the design, which amounted to 392 total runs to estimate the standard deviation. Figure 16 shows residual plots of applied load versus the estimated load in units of percent of full scale effect. To independently validate the model, confirmation runs purposefully employed unique loading combinations at a pressure level that was not used to construct the model. Two factor load combinations crossed with temperature and pressure were more rigorously tested for in the confirmation load schedule, to assess the shortcomings of neglecting three factor interactions in the model (where two of the factors are forces and one is a temperature or pressure). Results showed that the absence of these three factor interactions did not have a large impact on residual error. Table 9 shows the final two sigma accuracy quotes, both with and without the pressure and temperature terms included in the model. The model that was used without pressure and temperature originally contained 20 terms, made up of 5 main effects, 10 two factor interactions and 5 quadratic terms. The 20 term model was then reduced using a backwards selection method, from which two sigma accuracies were computed. From Table 9, it is clear that all five components have improved accuracies when pressure and temperature are included in the calibration model for each measurement component.
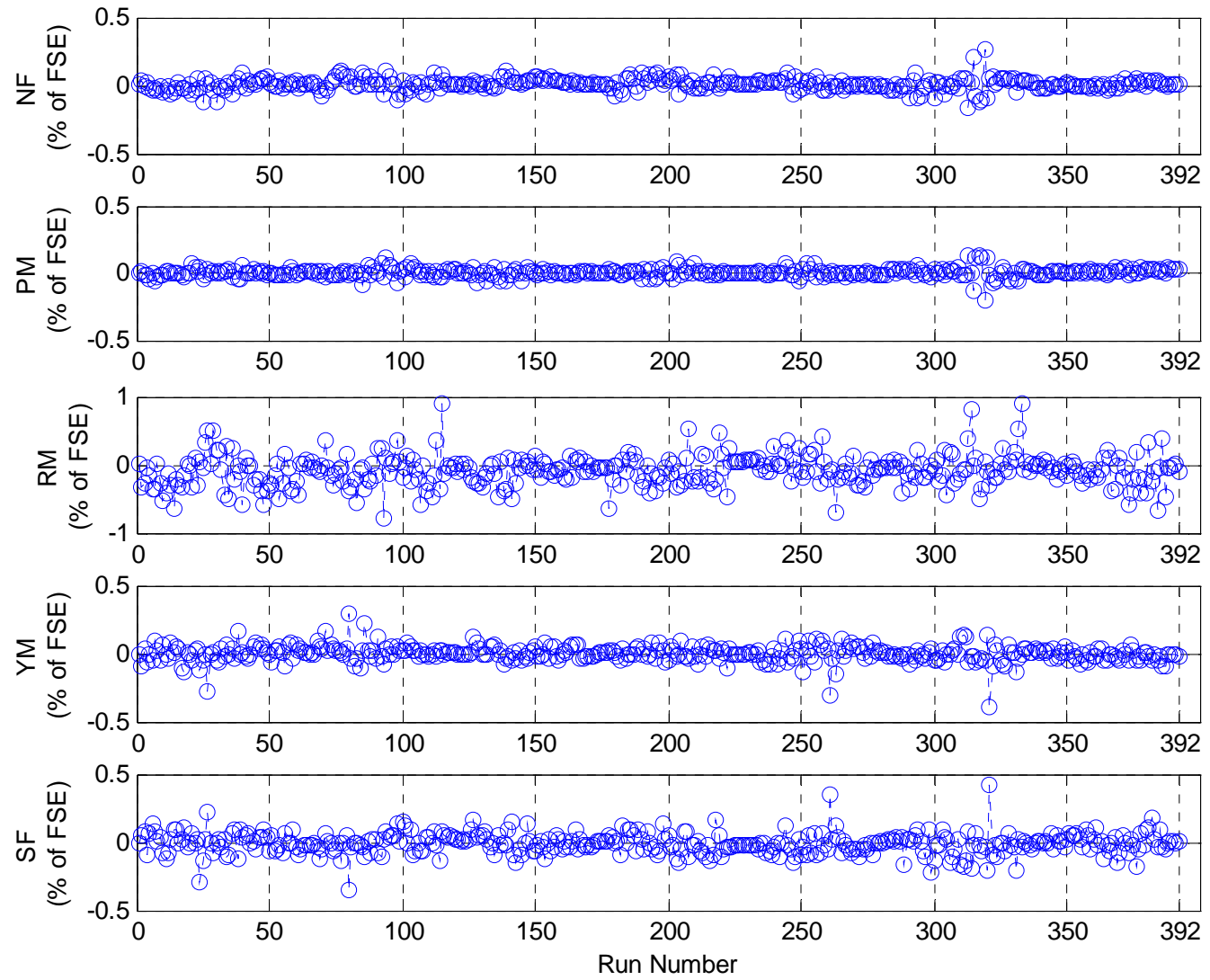

Figure 16. Residual plots using the final calibration model (with pressure and temperature terms). Total Residual vs. Calibration Run Number.

Table 9. Comparison of Balance Accuracies

\begin{tabular}{rccccc}
\hline & NF & PM & RM & YM & SF \\
\hline $2 \sigma(\%$ of FS $)$ w/ $p$ and T model terms & 0.085 & 0.063 & 0.450 & 0.118 & 0.155 \\
$2 \sigma(\%$ of FS $)$ w/o $p$ and T model terms & 0.120 & 0.115 & 0.463 & 0.180 & 0.202 \\
\hline
\end{tabular}

The final matrix containing the reduced model for each measurement component was originally developed in coded values, and at the completion of all data analysis the matrix was converted back into engineering units. The final 51x5 matrix containing both pressure and temperature correction terms was delivered to the 31-Inch Mach 10 
tunnel, and the data reduction code at the facility was modified in order to incorporate this larger matrix to allow for real-time data reduction. The incorporation of this $51 \times 5$ model matrix at the facility is one of the first instances at NASA LaRC where real-time data reduction was completed on-line at the tunnel during a test in order to correct for both pressure and temperature effects. While this modification to the standard data reduction process seems minor, it proves to be a major step in including higher order mathematical models within the data reduction code that have not been implemented in the past.

\section{Conclusion}

It has been shown that a new unique experimental design method has been applied to the calibration of a force transducer, that allows for accurately and precisely characterizing its performance while under the influence of applied loads, steady-state temperatures and applied balance cavity pressures. Previous balance calibrations conducted at NASA Langley have only been performed to determine the behavior of the balance with respect to applied loads and moments, and all steady-state temperature effects to be expected during testing conditions have been handled by applying a thermal sensitivity correction to the linear measurement sensitivity for each measurement component of the balance. This new technique fully characterizes the behavior of the balance, including both the linear behavior and two-factor interaction terms for each of the measurement responses.

This technique can directly be applied to any calibration, and specifically to any balance that needs to be characterized for wind-tunnel tests where other factors are suspected to potentially impact the quality/accuracy of the measurement data during the experiment. This paper presents the process to develop this innovative approach to force transducer calibration; detailing the transducer on-board compensation techniques, experimental design, mathematical modeling, and wind tunnel data reduction algorithm.

\section{Acknowledgments}

The authors would like to express sincere appreciation to everyone that has contributed to the many aspects of this project. The scope of this project required open lines of communication and cooperation amongst many personnel in order to successfully complete the experimental design and calibration of the SS-12 balance. The experimental design and calibration has been supported and funded by the National Force Measurement Technology Capability (NFMTC) and the NASA Engineering and Safety Center (NESC).

The authors would like to recognize the following individuals for their critical contributions in their respective expertise domains: Greg Jones for his extensive expertise and knowledge on the SVS and for his efforts in performing the balance calibration, Mark Schoenenberger for his valuable input in determining the calibration requirements directly related to his research efforts for the MSL program, and Matt Rhode for his testing expertise and knowledge of the previous tests utilizing the SS-12 balance.

\section{References}

${ }^{1}$ Dyakonov, A. A., Schoenenberger, M., Scallion, W. I., Van Norman, J. W., Novak, L. A., Tang, C. Y., “Aerodynamic Interference Due to MSL Reaction Control System”, AIAA 2009-3915, January 2009.

${ }^{2}$ Schoenenberger, M., Dyakonov, A. A., Buning, P., Scallion, W. I., Van Norman, J. W., “Aerodynamic Challenges for the Mars Science Laboratory Entry, Descent and Landing”, AIAA 2009-3914, June 2009.

${ }^{3}$ Rhew, R. D., "NASA LaRC Strain Gage Balance Design Concepts", $1^{\text {st }}$ International Symposium on Strain Gauge Balances, Pt. 2, March 1999, pp. 525-541.

${ }^{4}$ Guarino, J., "Calibration and Evaluation of Multi-component Strain-Gage Balances", NASA Interlaboratory Force Measurements Meeting, Jet Propulsion Laboratory, April, 1964.

${ }^{5}$ Booth, D., “ABCS Calibration Load Schedule for Force Type Balances”, AIAA 2008-844, January 2008.

${ }^{6}$ Parker, P. A., "A Single-Vector Force Calibration Method Featuring the Modern Design of Experiments", AIAA-20010170, January 2001.

${ }^{7}$ AIAA, "Recommended Practice: Calibration and Use of Internal Strain-Gage Balances with Application to Wind Tunnel Testing", AIAA R-091-2003.

${ }^{8}$ Montgomery, D. C., Design and Analysis of Experiments $7^{\text {th }}$ Ed., 2009, John Wiley \& Sons, Inc., New York.

${ }^{9}$ Myers, R. H., Montgomery, D. C., Anderson-Cook, C. M., Response Surface Methodology $3^{\text {rd }}$ Ed., 2009, John Wiley \& Sons, Inc., New York.

${ }^{10}$ Kowalski, S. M., Parker, P. A., and Vining, G. G. "Tutorial on Split-Plot Experiments," QualityEngineering, 19, 2007, pp. $1-15$. 
${ }^{11}$ Parker, P. A., Kowalski, S. M., and Vining, G. G. "Unbalanced and Minimal Point Equivalent Estimation of Second-Order Split-Plot Designs," Journal of Quality Technology, 39, 2007, pp. 376-388.

${ }^{12}$ Parker, P. A., Anderson-Cook, C. M., Robinson, T. J., and Liang, L., "Robust Split-Plot Designs," Quality and Reliability International, 24, 2008, pp. 107-121.

${ }^{13}$ Parker, P. A. "Response Surface Design and Analysis in the Presence of Restricted Randomization: Equivalent Split-Plot Designs" (dissertation etd-03302005-194026). Blacksburg, VA: Virginia Polytechnic Institute and State University.

${ }^{14}$ Bergman, R., Philipsen, I., "An Experimental Comparison of Different Load Tables for Balance Calibration", $7^{\text {th }}$ International Symposium on Strain Gauge Balances, April 2010.

${ }^{15}$ Montgomery, D. C., Peck, E. A., and Vining, G. G., Introduction to Linear Regression Analysis $4^{\text {th }}$ Ed., John Wiley \& Sons, Inc., New York.

${ }^{16}$ Ulbrich, N., "Regression Model Optimization for the Analysis of Experimental Data", AIAA 2009-1344, January 2009.

17 DeLoach, R., "The Role of Hierarchy in Response Surface Modeling of Wind Tunnel Data", AIAA 2009-931, January 2009.

${ }^{18}$ Moore, T. C., "Recommended Strain Gage Application Procedures for Various Langley Research Center Balance and Test Articles", NASA TM-2004-213017, May 2004. 